\title{
A Study on the Optimization of Exposure condition at Lumbar projection Using Blind Test
}

\author{
Jikoon Park*, Kyotae Kim**, Inchan Yoon*, Ilhong Choi*, Hyungjin Jung*, Sangsik Kang*, \\ Sicheul Noh*, Bongjae Jung* \\ Dept. of Radiological Science, International University of Korea* \\ Dept. of Hybrid Medicine af th Science, Inje University**
}

\section{블라인드 테스트를 통한 요추 검사 시 조사 조건의 최적화 연구 \\ 박지군*, 김교태**, 윤인찬*, 최일홍*, 정형진*, 강상식*, 노시철*, 정봉재* \\ 한국국제대학교 방사선학과*, 인제대학교 융합의과학**}

\begin{abstract}
This study intended to investigate the optimum conditions for lumbar test that has the highest level of irradiation conditions among general test sites. To to this, the most widely used irradiation conditions in terms of statistics were set as standards; test groups applied with DMF were selected; tests groups suitable for clinical trials were selected by using suggested patient dose. Blind tests were conducted by 10 specialists and radiologists. The results suggested that under the optimum conditions, the radiation dose reduction of 2.09 mGy, $4.42 \mathrm{mGy}$ and $3.65 \mathrm{mGy}$ can be achieved in forward-backward test, lateral test and 4-direction test, respectively. There is a need of further studies on the optimization of irradiation conditions in accordance with the conditions of patients.
\end{abstract}

Key Words: Digital Radiography, Lumbar Projection, ALARA,

\section{요 야}

본 연구에서는 일반 촬영 검사 부위 중 조사 조건이 가장 높은 요추 검사에서, 최적의 조사 조건에 대하여 알아보고 자 하였다. 이를 위해 통계적으로 많이 이용하고 있는 조사 조건을 기준으로 선정하였고, 선량 변화 인자를 적용한 실 험군을 선정하였으며, 환자선량 권고량을 활용하여 임상에 적합한 실험군을 선별하였다. 블라인드 테스트는 전문의 및 방사선사 10 명에 의해 수행되었고, 결과 최적화된 조사 조건에서, 전후 방향 검사의 경우 $2.09 \mathrm{mGy}$, 측방향 검사의 경우 $4.42 \mathrm{mGy}$, 사방향 검사의 경우 $3.65 \mathrm{mGy}$ 만큼의 선량 저감화가 가능할 것으로 사료된다. 차후에는 환자의 상태 에 따른 조사 조건의 최적화 연구가 수행되어야 할 것으로 사료된다.

중심단어: 디지털 방사선촬영, 요추 검사, 최적화 방호 원칙

\section{I. 서 론}

X-ray 발견 이 후 공학, 이학, 의학 등 융합 과학의
복합적인 진보에 따라 영상 진단 기기의 상수용체 기 술이 아날로그 방식에서 디지털 방식으로 급속히 발 전하였고, 현재도 다양한 첨단 의료 영상 기술들이 연 구자들에 의해 연구되어 소개되고 있다 ${ }^{[1]}$. 과거 아날 
로그 방식의 필름-증감지(Film-Screen System, $\mathrm{F} / \mathrm{S}$ System) 기술의 경우 방사선 조사 조건이 필름 영상 품 질에 직접적인 영향을 미쳤으나 ${ }^{[2]}$, 디지털 방식의 방 사선촬영 기술인 컴퓨터 방사선촬영(Computed Radiography, CR)과 디지털 방사선촬영(Digital Radiography, DR)의 경우는 기존 F/S System에 비해 훨 씬 넓은 대역폭을 가지고 있어 부적절한 노출 조건에 서도 충분한 진단능을 가지는 영상 품질을 제공할 수 있다 ${ }^{[3],[4]}$. 이러한 장점은 영상 품질 관점에서는 우수하 지만, 환자선량의 관점에서는 의료영상품질의 큰 차이 없이 환자에게 불필요한 노출이 발생하는 선량 크리 프(Dose Creep) 현상이 나타난다 ${ }^{[5]}$. 의료방사선에 의한 방사선량은 의료의 특수성을 고려하여 국제적으로 선 량한도를 정하지 않고 있으낱], 국내·외의 여러 기관 에서 영상 품질의 향상과 환자 피폭선량 저감화를 위 해 많은 노력을 기울이고 있다. 국외의 경우, 국제원자 력기구(International Atomic Energy Agency, IAEA) 및 세계보건기구(World Health Organization, WHO) 등에서 공동으로 의료피폭에 대한 저감화를 위한 Guidance level에 대하여 마련하였고, 국제방사선방어위원회 (International Commission on Radiological Protection, ICRP)에서는 의료분야에서의 방사선방호에 관하여 권 고안을 발간하였다 ${ }^{[7],[8]}$. 또한 국내의 경우, 식품의약품 안전처에서 일반 촬영 시 검사 부위에 따른 환자선량 권고량(Patient Dose Reference Levels, DRL)에 따른 가 이드라인을 발간하였다 ${ }^{[9]}$. 그러나 이는 환자선량의 저 감화에 따른 영상 품질의 영향을 다루고 있지 않으며, 환자선량 권고량을 만족하는 적정한 조사 조건에 대 하여 확립되어 있지 않는 실정이다.

이에 본 연구에서는 현 임상에서 일반 촬영 검사 부 위 중 조사 조건이 가장 높은 요추 검사에 대하여, 조 사조건과 선량 변화 인자(Factor)를 고려한 실험군 (Experiment Group)을 선정 후 피부입사선량(Entrance Skin dose, $\mathrm{ESD})$ 을 측정하고, 국내에서 제시하고 있는 환자선량 권고량과의 비교를 통하여 환자피폭선량을 평가함으로써 최적화 방호 원칙(as low as Reasonably Achievable, ALARA)을 지키는 동시에 우수한 품질의 의료 영상을 획득 할 수 있는 최적의 조사 조건에 대 하여 알아보고자 한다.

\section{II. 연구방법}

식품의약품안전처에서 제시하고 있는 일반 영상의 학검사 중 요추 검사 시 통계적으로 가장 많이 이용하 고 있는 조사 조건을 기준으로 선정하였고, 선량 변화 인자인 관전압 및 관전류량의 변화를 실험군으로 선 정하였다. 이 후 조사 조건에 따른 피부입사선량을 측 정 후, 환자선량 권고량과 비교를 통하여 권고량 보다 낮은 실험군을 선별하였으며 이를 블라인드 테스트를 통하여 최적의 조사 조건을 도출하였다.

\section{1. 실험 기기}

본 연구에서 흡수선량을 측정하기 위하여 일반 촬 영 장비용 센서(IBA, German)을 이용하였고, 관전류량 및 튜브 출력량을 측정하기 위하여 관전류량 센서 ((IBA, German))을 이용하였다. 또한 X-선관은 Toshiba 장비의 $\mathrm{E} 7252 \mathrm{X}$ 를 이용하였고, 영상 획득을 위한 상수 용체 Stand Bucky는 DK medical를 활용하였으며, 복부 및 요추 범용 모델인 팬텀 RS-133T를 이용하였다. 실 험에 이용된 장비를 Fig. 1에 나타내었다.

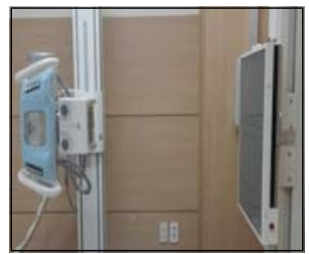

(a) X-ray Tube and Stand bucky

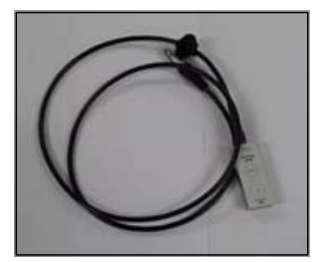

(c) XR-Sensor

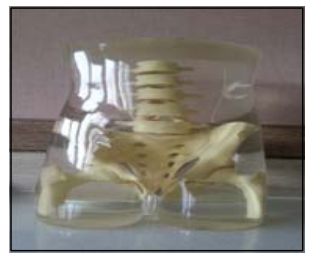

(b) Abdomen Phantom

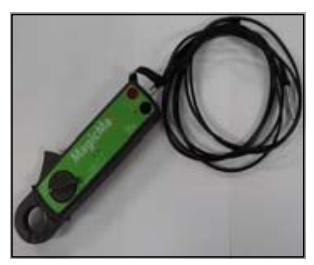

(d) mAs-Sensor
Fig. 1. To Used Equipment for Experiment.

\section{2. 실험 방법}

\section{1 조사 조건 및 실험 방법}

식품의약품안전처에서 제시하고 있는 일반 영상의학검사 
Table 1. Selection of Experimental Group for change of Dose factor

\begin{tabular}{|c|c|c|c|c|c|c|}
\hline \multirow{2}{*}{ Group $\quad$ Factor } & \multicolumn{2}{|c|}{ AP Projection } & \multicolumn{2}{|c|}{ LAT Projection } & \multicolumn{2}{|c|}{ OBL Projection } \\
\hline & $\mathrm{kVp}$ & mAs & $\mathrm{kVp}$ & mAs & $\mathrm{kVp}$ & mAs \\
\hline Condition 1 & 65 & 16 & 68 & 25 & 66 & 20 \\
\hline Condition 2 & 65 & 20 & 68 & 32 & 66 & 25 \\
\hline Condition 3 & 65 & 25 & 68 & 40 & 66 & 32 \\
\hline Condition 4 & 65 & 32 & 68 & 50 & 66 & 40 \\
\hline Condition 5 & 65 & 40 & 68 & 63 & 66 & 50 \\
\hline Condition 6 & 70 & 16 & 74 & 25 & 71 & 20 \\
\hline Condition 7 & 70 & 20 & 74 & 32 & 71 & 25 \\
\hline Condition 8 & 70 & 25 & 74 & 40 & 71 & 32 \\
\hline Condition 9 & 70 & 32 & 74 & 50 & 71 & 40 \\
\hline Condition 10 & 70 & 40 & 74 & 63 & 71 & 50 \\
\hline Condition 11 & 75 & 16 & 80 & 25 & 77 & 20 \\
\hline Condition 12 & 75 & 20 & 80 & 32 & 77 & 25 \\
\hline Condition 13 & 75 & 25 & 80 & 40 & 77 & 32 \\
\hline Condition 14 & 75 & 32 & 80 & 50 & 77 & 40 \\
\hline Condition 15 & 75 & 40 & 80 & 63 & 77 & 50 \\
\hline Condition 16 & 80 & 16 & 86 & 25 & 82 & 20 \\
\hline Condition 17 & 80 & 20 & 86 & 32 & 82 & 25 \\
\hline Condition 18 & 80 & 25 & 86 & 40 & 82 & 32 \\
\hline Condition 19 & 80 & 32 & 86 & 50 & 82 & 40 \\
\hline Condition 20 & 80 & 40 & 86 & 63 & 82 & 50 \\
\hline Condition 21 & 85 & 16 & 92 & 25 & 88 & 20 \\
\hline Condition 22 & 85 & 20 & 92 & 32 & 88 & 25 \\
\hline Condition 23 & 85 & 25 & 92 & 40 & 88 & 32 \\
\hline Condition 24 & 85 & 32 & 92 & 50 & 88 & 40 \\
\hline Condition 25 & 85 & 40 & 92 & 63 & 88 & 50 \\
\hline
\end{tabular}

중 요추 전후 방향 검사(Anterioposterior Projection, $\mathrm{AP})$ 및 요추 측방향 검사(Lateral Projection, LAT) 그리 고 사방향 검사(Oblique Projection, $\mathrm{OBL}$ )에 대하여 통 계적으로 가장 많이 이용하고 있는 조사 조건을 기준 으로 대조군을 선정하였다 ${ }^{[8]}$. 전후 방향 검사의 경우 관전압 $75 \mathrm{kVp}$, 관전류 $250 \mathrm{~mA}$, 조사 시간 $0.125 \mathrm{sec}$ 로 선정하였고, 측방향 검사의 경우 관전압 $80 \mathrm{kVp}$, 관전 류 $320 \mathrm{~mA}$, 조사 시간 $0.16 \mathrm{sec}$ 으로 선정하였으며, 사 방향 검사의 경우 관전압 $77 \mathrm{kVp}$, 관전류 $250 \mathrm{~mA}, 0.16$ $\mathrm{sec}$ 으로 선정하였다. 또한 실험군은 선량 변화 인자 중 관전압에 대하여 관전압 $15 \%$ 법칙 $(\mathrm{kVp} \quad 15 \%$ law's)을 적용하였고, 및 관전류량에 대하여 관전류량 $30 \%$ 법 칙 $(\mathrm{mAs} \mathrm{30 \%} \mathrm{law's)을} \mathrm{적용하여} \mathrm{선정하였다.} \mathrm{선정} \mathrm{결과}$ 관전압의 경우 전후 방향 검사는 $5 \mathrm{kVp}$, 측방향 검사 는 $6 \mathrm{kVp}$, 사방향 검사는 $5 \mathrm{kVp} \sim 6 \mathrm{kVp}$ 단위로 실험 군을 선정하였다. 또한, 관전류량의 경우 전후 방향 검 사에서는 $16 \mathrm{mAs}, 20 \mathrm{mAs}, 25 \mathrm{mAs}, 32 \mathrm{mAs}, 40 \mathrm{mAs}$, 측방향 검사는 $25 \mathrm{mAs}, 32 \mathrm{mAs}, 40 \mathrm{mAs}, 50 \mathrm{mAs}, 63$ $\mathrm{mAs}$, 사방향 검사는 $20 \mathrm{mAs}, 25 \mathrm{mAs}, 32 \mathrm{mAs}, 40 \mathrm{mAs}$,
$50 \mathrm{mAs}$ 로 실험군을 선정하였다. 선정한 실험군에 대 한 결과는 Table 1 에 나타내었다.

\section{2 피부입사선량 측정 및 환자선량 권고량과 비교}

(1) 피부입사선량 $(\mathrm{ESD})$ 측정

피부입사선량 $(\mathrm{ESD})$ 은 피부 영역에 대한 평균 흡수 선량이며, 유해한 조직반응(Deterministic Effect)에 대한 위험이 있는 경우 반드시 평가해야 한다. 피부입사선 량(ESD)은 Magicmax Universal 모델명 Multimeter Magicmax Basic Unit에 연결된 일반 촬영 장비용 센서 (XR-Sensor)을 이용하여 흡수선량(Absorbed Dose, AD) 를 측정하였다. XR-Sensor는 전압에 대하여 $40 \mathrm{kV}$ $160 \mathrm{kV}$ 까지 측정이 가능하고, 선량에 대해서 $50 \mathrm{nGy}$ $50 \mathrm{~Gy}$ 까지 측정이 가능한 장비이다 ${ }^{[9]}$. 또한, 전류에 대 하여 $10 \mathrm{~mA}-2000 \mathrm{~mA}$ 까지 측정이 가능한 $\mathrm{mAs}$-Sensor 을 이용하여 관전류량 $(\mathrm{mAs})$ 및 튜브 출력량을 측정하 였다. 실험은 상수용체 Stand Bucky DR System 전면에 피사체를 위치시키고 X-ray Tube와 상수용체 거리 
(Source to Image distance, SID)를 40 inch로 설정한 후 조사되는 X-ray 중심축에 맞추어 방사선 측정용 멀티 메터를 이용하여 측정하였다. 실험에 대한 모식도를 Fig. 2에 나타내었다.

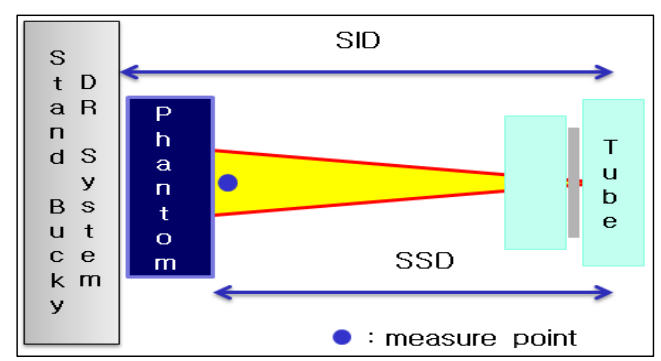

Fig. 2. Schematic for Experiment.

피부입사선량의 계산은 다음과 같은 수식으로 산출 하였다 ${ }^{[10]}$.

$E S D=$ Output $\times\left(\frac{k V}{X}\right)^{2} \times m A s \times\left(\frac{100}{S S D}\right)^{2} \times B S F$

상기 수식에서 $\mathrm{ESD}$ 는 피부입사선량을 의미하고, Output는 관전압 지시치에서의 빔 축을 따라 튜브 초 점으로부터 $40 \mathrm{inch}$ 거리에서 측정된 $\mathrm{mAs}$ 당 튜브 출 력을 의미한다, 또한, $\mathrm{X}$ 는 관전압 지시치를 의미하고 $\mathrm{SSD}$ (Source to Skin distance)는 초점(Source)-환자 표면 거리(Skin)를 의미한다. BSF(Backscatter factor)는 후방 산란계수를 의미하며, 본 실험에서는 후방 산란계수에 대하여, EUR 16262에서 규정하고 있는 진단에너지 영 역에서의 상수인 1.35 를 적용하였다 ${ }^{[11]}$.

(2) 환자선량 권고량과 비교

최근 국내 실정에 맞는 환자선량 권고량 가이드 라 인을 발간되었는데, 요추 검사 시 검사별로 환자선량 을 국내 병원에서 이용하고 있는 조사 조건을 표준 통 계 소프트웨어 프로그램(Statistical Package for Social Science, SPSS)을 이용하여 통계적 자료로 제시하고 있 고, 환자선량 권고량은 국제기구에서 권고하는 제 3 사 분위값으로 확립하고 있다. 국내 요추 검사에서 권고 되고 있는 환자선량은 전후 방향 검사의 경우 4.08 $\mathrm{mGy}$ 이고, 측방향 검사의 경우 $10.53 \mathrm{mGy}$ 이며, 사방향 의 경우 $6.35 \mathrm{mGy}$ 로 권고하고 있다. 이러한 환자선량 권고량과 측정된 피부입사선량의 비교를 통해 실험군 중 임상의 적용 가능성을 평가하였다.

\section{3 블라인드 테스트를 통한 영상화질평가}

영상화질을 평가하기 위하여 피부입사선량과 환자 선량 권고량의 비교 및 분석을 통해 선별한 실험군에 대하여 팬텀 영상을 획득하였고, 블라인드 테스트를 실시하였다. 블라인드 테스트를 위한 판독 영상은 의 료영상저장전송시스템(Picture Archiving Communication System, PACS)에서 대조도를 조절을 시행하지 않은 영 상으로, 전문의 7 명 그리고 임상 경력 10년 이상의 방 사선사 3 명에게 의뢰하였다. 평가표 문항의 항목은 6 개로 선정하였고, 항목 별로 점수를 부여하여 합산하 였으며, 이를 요추 검사별로 분석하였다. 블라인드 테 스트에 이용한 평가표를 Table 2에 나타내었다 ${ }^{[12]}$.

Table 2. Evaluating method of Lumbar spine

\begin{tabular}{|c|c|c|c|c|}
\hline \multirow{2}{*}{ Check List } & \multicolumn{4}{|c|}{ Score } \\
\hline & 1 & 2 & 3 & 4 \\
\hline \multicolumn{5}{|l|}{$\begin{array}{l}\text { Vertebral Body is it possible to observe } \\
\text { without insufficient density? }\end{array}$} \\
\hline \multicolumn{5}{|l|}{$\begin{array}{l}\text { Concentration of the appropriate } \\
\text { (outside bone) Fat area? }\end{array}$} \\
\hline \multicolumn{5}{|l|}{$\begin{array}{c}\text { Inter Ver tebral Disk Space is possible } \\
\text { to observed clearly? }\end{array}$} \\
\hline \multicolumn{5}{|l|}{$\begin{array}{c}\text { Concentration of Pelvic bone } \\
\text { is appropriate? }\end{array}$} \\
\hline \multicolumn{5}{|l|}{$\begin{array}{l}\text { Spinous process can be identified by the } \\
\text { state is not an excessive concentration? }\end{array}$} \\
\hline Overall image quality is suitable? & & & & \\
\hline
\end{tabular}

\section{III. 결과 및 고찰}

\section{1. 피부입사선량 측정 및 환자선량 권고량과 비교}

(1) 피부입사선량(ESD) 측정

기준 조사 조건의 실험 결과, 전후 방향 검사의 경 우 $5.84 \mathrm{mGy}$ 가 측정되었고, 측방향 검사의 경우 14.87 $\mathrm{mGy}$ 가 측정되었으며, 사방향 검사의 경우 $10.06 \mathrm{mGy}$ 가 측정되었다. 선정한 다수의 실험군에 대하여 흡수 선량을 측정하고 피부입사선량을 도출하였으며, 이를 상대값(Relative Value, RV)으로 Fig. 3에 나타내었다. 실 험 결과, 전후 방향 검사의 경우 조건 1 에서 조건 13 까지 그리고 조건 16 , 조건 17 , 조건 18 , 조건 21 이 기 
준 조건 보다 낮은 피부입사선량을 가지는 것으로 나 타났다. 하지만 측방향 검사 및 사방향 검사의 경우 조건 1 에서 조건 13 까지 그리고 조건 16 , 조건 17 , 조 건 21이 기준 조건 보다 낮은 피부입사선량을 가지는 것으로 나타났으나, 조건 18 의 경우, 각 각 $8.11 \%$, $17.62 \%$ 더 많은 피폭을 받는 것으로 나타났다. 이러한 결과는 피폭선량 저감화 및 선량 크리프 현상을 제거 하기 위해서 조사 조건 인자 중 관전류량은 낮추고 관 전압을 높이는 방법이 유의성을 가지는 것으로 사료 된다.

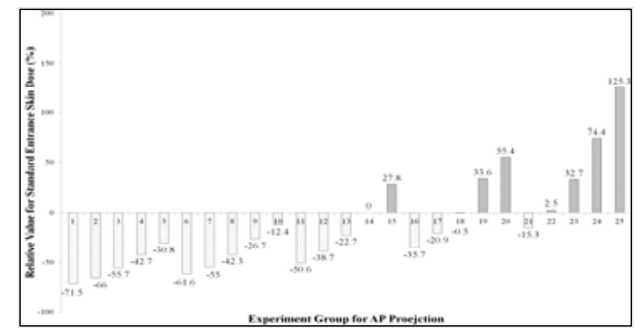

(a) AP Projection

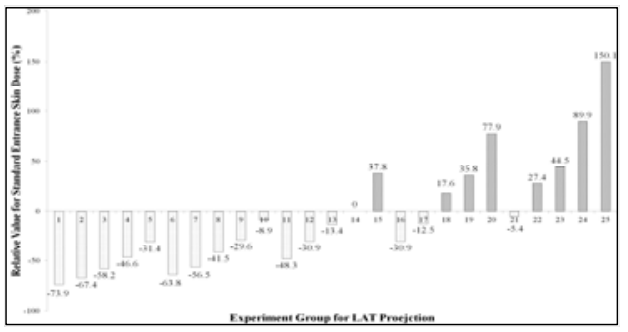

(b) LAT Projection

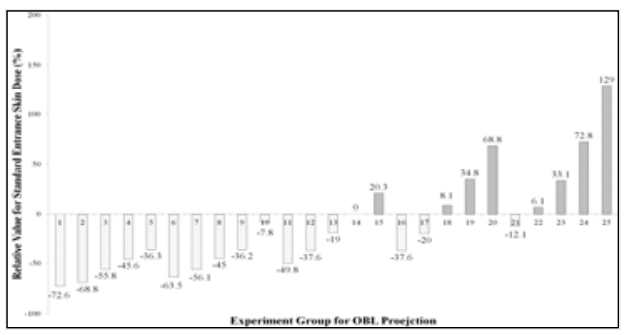

(c) OBL Projection

Fig. 3. Relative Value of the ESD at AP Projection(a), LAT Projection(b) and OBL Projection(c).

(2) 환자선량 권고량과 비교

국내 요추 검사에서 권고되고 있는 환자선량은 전 후 방향 검사의 경우 $4.08 \mathrm{mGy}$ 이고, 측방향 검사의 경 우 $10.53 \mathrm{mGy}$ 이며, 사방향의 경우 $6.35 \mathrm{mGy}$ 로 권고하 고 있다. 환자선량 권고량과 측정된 요추 검사별 피부
입사선량의 비교 및 분석 결과 만족하는 실험군은 조 건 1 조건 9, 그리고 조건 11 , 조건 12 , 그리고 조건 16으로 선별되었다. 선별된 실험군의 결과, 전후 방향 검사에서는 상대적으로 $0.97 \%$ 59.23\%로 나타났고, 측방향 검사에서는 상대적으로 $2.51 \% \sim 63.24 \%$ 로 나 타났으며, 사방향 검사에서는 상대적으로 $1.21 \%$ $56.68 \%$ 로 나타났다.

\section{2. 블라인드 테스트를 통한 영상화질평가}

블라인드 테스트 결과, 실험군의 조사 조건이 증가 함에 따라 평가 점수가 향상되는 것을 확인할 수 있었 고, 일정 조건 이상에서는 포화되는 형태로 나타난다. 요추 검사별 기준 조건의 영상을 Fig. 4에 나타내었고, 선별된 실험군에 대한 평가 점수를 Table 3에 나타내 었다.

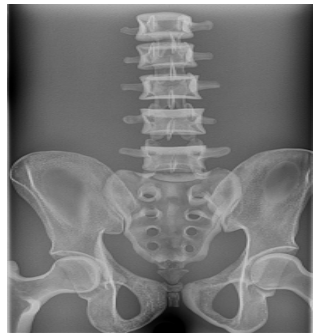

(a) AP Projection

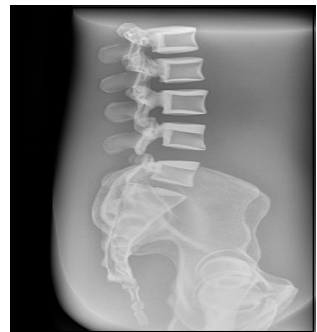

(b) LAT Projection

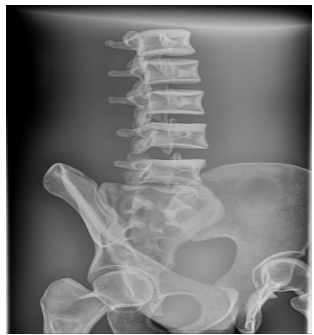

(c) OBL Projection

Fig. 4. Image of evaluated by AP Projection(a), LAT Projection(b) and OBL Projection(c). 
기준 조건인 조건 14 을 이용하여 검사한 팬텀 영상 의 평가 결과는 전후 방향 검사의 경우 38 점, 측방향 검사의 경우 50 점, 사방향 검사의 경우 50 점으로 평가 되었다. 또한 선별된 실험군들의 조사 조건을 이용하 여 검사한 팬텀 영상의 평가 결과, 전후 방향 검사에 서는 조건 16이 40점으로 가장 높은 점수를 획득하였 고, 측방향 검사에서는 조건 9 가 50점으로 가장 높은 점수를 획득하였으며, 사방향 검사에서는 조건 9 가 50 점으로 가장 높은 점수를 획득하여 최적 조건임을 확 인하였다.

Table 3. Result of image score on Lumbar projection

\begin{tabular}{llll}
\hline & \multicolumn{3}{c}{ Projection } \\
\cline { 2 - 4 } Group & AP & LAT & OBL \\
\hline Condition 1 & 32 & 18 & 26 \\
\hline Condition 2 & 32 & 18 & 28 \\
\hline Condition 3 & 32 & 22 & 32 \\
\hline Condition 4 & 34 & 22 & 34 \\
\hline Condition 5 & 36 & 24 & 40 \\
\hline Condition 6 & 32 & 36 & 32 \\
\hline Condition 7 & 32 & 38 & 32 \\
\hline Condition 8 & 32 & 46 & 40 \\
\hline Condition 9 & 34 & 50 & 50 \\
\hline Condition 10 & 36 & 50 & 50 \\
\hline Condition 11 & 32 & 42 & 46 \\
\hline Condition 12 & 36 & 46 & 46 \\
\hline Condition 13 & 36 & 50 & 50 \\
\hline Condition 14 & 38 & 50 & 50 \\
\hline Condition 15 & 50 & 50 & 50 \\
\hline Condition 16 & 40 & 46 & 42 \\
\hline Condition 17 & 38 & 50 & 46 \\
\hline Condition 18 & 40 & 50 & 50 \\
\hline Condition 19 & 50 & 50 & 50 \\
\hline Condition 20 & 50 & 50 & 50 \\
\hline Condition 21 & 42 & 50 & 42 \\
\hline Condition 22 & 42 & 50 & 42 \\
\hline Condition 23 & 50 & 50 & 50 \\
\hline Condition 24 & 50 & 50 & 50 \\
\hline Condition 25 & 50 & 50 & 50 \\
\hline & & & \\
\hline
\end{tabular}

\section{$\mathrm{IV}$. 결 론}

본 연구에서는 현 임상에서 일반 촬영 검사 부위 중 조사 조건이 가장 높은 요추 검사에 대하여, 최적화 방호 원칙을 준수하며 우수한 품질의 의료 영상을 획 득 할 수 있는 최적의 조사 조건에 대하여 알아보고자 하였다. 이를 위하여 통계적으로 가장 많이 이용하고
있는 조사 조건을 기준으로 선정하고, 선량 변화 인자 를 적용하여 실험군을 선정하였으며, 환자선량 권고량 을 만족하는 실험군에 대하여 블라인드 테스트를 통 해 최적의 조사 조건을 도출하고자 하였다.

실험 결과 실험군의 변화 인자 중 관전류량의 변화 보다는 관전압의 변화 시 피부입사선량에 더 많은 영 향을 미치고, 조사 조건이 증가함에 따라 평가 점수가 향상되나, 일정 조건 이상에서는 포화되는 것으로 나 타났다. 이러한 결과는 조사 조건 설정 시 관전류량을 증감하기 보다는 관전압에 대하여 증감하는 방법이 바람직하다. 또한 조사 조건 증가는 영상 품질을 우수 하게 하는 반면에, 적정 조건 이상의 이용은 불필요한 환자선량을 초래할 것으로 사료된다. 블라인드 테스트 결과, 요추 검사별 최적화된 조사 조건은 전후 방향 검사의 경우 $80 \mathrm{kVp}, 16 \mathrm{mAs}$ 이고, 기준 조사 조건에 비하여 약 $2.09 \mathrm{mGy}$ 만큼 선량 저감화가 가능할 것으 로 사료된다. 측방향 검사의 경우 $74 \mathrm{kVp}, 50 \mathrm{mAs}$ 이며, 기준 조사 조건에 비하여 약 $4.42 \mathrm{mGy}$ 만큼 선량 저감 화가 가능할 것으로 사료된다. 사방향 검사의 경우 71 $\mathrm{kVp}, 40 \mathrm{mAs}$ 로 확인되었고, 기준 조건에 비하여 약 3.65 $\mathrm{mGy}$ 만큼 선량 저감화가 가능할 것으로 사료된다. 그 러나 최적화된 조사 조건은 $175 \mathrm{~cm}, 70 \mathrm{~kg}$ 인 표준 환자 에서는 만족하지만, 환자의 상태에 따라 최적화된 조 사 조건은 변화할 수 있다. 그러므로 차후에는 환자의 상태를 변화 인자(factor)로 선정하고, 이에 따른 조사 조건 연구를 통하여 조사 조건의 최적화 연구를 수행 하여야 할 것으로 사료된다.

\section{참고문헌}

[1] JiKoon Park, "Advanced Digital Medical Imaging Technologies", KyeongNam Radiological Technologist Association Academic publication of 2013, pp 29 - 33, 2013.

[2] SunSook Lee, Joon Huh, "The Study on the Image Quality and Patient Exposure Dose of Chest Radiography in Korea", Korean Society of Radiological Science, Vol. 18, No. 2, pp 49 - 59, 1995

[3] JongIn Lee, "A Study on the Dose Indicator for Digital radiography", The Graduate School Yonsei University, 2008.

[4] JiKoon Park, "The signal property and structure design of CsI:Na/a-Se for diagnostic x-ray imaging", J. Korean. soc. radiol, Vol. 4, pp 33-36, 2009 
[5] Report in AAPM Task Group \#116, "Recommended Expo -sure Indicator for Digital Radiography", 2009.

[6] ICRP Publication 60 : "Recommendations of the Inter -national Commission on Radiological Protection", Oxford, 1991.

[7] IAEA Safety Series No.115 : "International Basic Safety Standards for Protection against Ionizing Radiation and for the Safety of Radiation Sources", Vienna, 1996.

[8] ICRP Publication 103: Recommendations of the Inter -national Commission on Radiological Protection, Oxford, 2007.

[9] "Patient Dose Reference Levels Guidelines of General Radiology", Korea Food \& Drug Administration, Radiation safety management series, No. 30, 2012.

[10] "Radiation dosimetry Multimetor(Magicmax Universal) Product Specification", JSB Medics Co, JSB Medical Device, 2013.

[11] SangTae Kim, BeomHui Han, "Evaluation of the Patient Dose in Case of Standard Radiographic Examinations Using CR and DR", Korean Society of Radiological Science, Vol. 33, No. 3, pp. 173-177 2010.

[12] "European Commission : European guidelines on quality criteria for diagnostic radiographic images", EUR 16260 EN (Brussels : EC), 1996.

[13] InChan Yoon, "A Study for Patient Dose By Exposure Field Size and Image Quality", The Graduate School International University of Korea, 2013. 